\title{
ENSINO DE CIÊNCIAS E BIOLOGIA E O CENÁRIO DE RESTAURAÇÃO CONSERVADORA NO BRASIL: INQUIETAÇÕES E REFLEXÕES
}

\author{
Rodrigo Cerqueira do Nascimento Borba ${ }^{i}$ \\ Maria Carolina Pires de Andrade ${ }^{\mathrm{ii}}$ \\ Sandra Escovedo Selles ${ }^{\text {iii }}$
}

\begin{abstract}
Resumo: O presente artigo aciona o conceito de restauração conservadora elaborado por Michael Apple (2001; 2015; 2017) para refletir sobre os rumos das políticas curriculares que interpelam as disciplinas escolares Ciências e Biologia na atualidade. Aproximando-nos de tensões que são fruto das históricas disputas entre o público e o privado na educação brasileira, debatemos incursões recentes do conservadorismo sobre os currículos dessas disciplinas. Assim, apresentamos e discutimos tentativas de constrangimento ao ensino de determinadas temáticas que são atravessadas por controvérsias socioculturais: evolução biológica; corpo humano, saúde e diferença; diversidade étnico-racial. Por fim, também sinalizamos severas ameaças aos princípios democráticos que regem a educação do país.
\end{abstract}

Palavras-chave: Ensino de Ciências e Biologia; restauração conservadora; currículo; BNCC.

\section{TEACHING OF SCIENCES AND BIOLOGY AND THE SCENARIO OF CONSERVATIVE RESTORATION IN BRAZIL: REFLECTIONS AND REFLECTIONS}

\begin{abstract}
This article discusses the concept of conservative restoration by Michael Apple (2001, 2015, 2017) to reflect on the paths of current curricular policies for the school subjects sciences and biology. Taking into account that tensions are part of the historical disputes between the public and the private sectors in the Brazilian education, the article debates recent incursions of conservatism on the curricula of these school subjects. Thus, we present and discuss some conservative constraints to the teaching of themes that are crossed by sociocultural controversies such as biological evolution; human body, health and difference; ethnic-racial diversity. This paper also points out serious threats to the democratic principles that rule the Brazilian education.
\end{abstract}

Keywords: Teaching Science and Biology; conservative restoration; curriculum; BNCC. 


\section{Introdução}

Escrever sobre as políticas públicas educacionais pensando especificamente o campo do ensino de Ciências e Biologia é algo que nada tem de trivial. Em primeiro lugar porque, como afirmam Marandino, Selles e Ferreira (2009), existem muitas versões do que denominamos "ensino de Ciências e Biologia". Cada versão, histórica e concretamente inserida em diferentes cenários socioculturais, produz sentidos e assume significados distintos, a depender também dos sujeitos e das instituições com que dialoga. Dessa forma, compreendemos que, dentro e/ou fora dos contextos escolares, é cotidianamente engendrada, disseminada e legitimada por uma variedade de conhecimentos e de práticas com diversas finalidades.

Em segundo lugar porque, como afirma Ferreira (2014, p. 187), os currículos são "construções sócio-históricas que produzem e hegemonizam significados sobre quem somos e sobre aquilo que sabemos" (FERREIRA, 2014, p. 187). Nesse sentido, os currículos nunca são neutros ou meras prescrições; são condicionados epistemológica, política, social, econômica, ética e esteticamente. Assim, ao refletir relações de poder, não são estáticos e imunes a debates e conflitos em torno das questões que atravessam a sociedade e as ciências de referência (SELLES e FERREIRA, 2005). Tanto o currículo quanto as disciplinas escolares são palco de disputas e negociações nos processos de seleção de conteúdos e métodos de ensino, e são atravessados, portanto, por interesses de grupos sociais e de instituições historicamente situadas (GOODSON, 1995; 1997).

Desafiador também é pensar e dissertar sobre o avanço do conservadorismo nas políticas públicas educacionais, mormente a partir do polêmico impedimento da presidente Dilma Roussef em 2016, quando foram trazidas novas complexidades ao já nada simples cenário social brasileiro. Desde então, uma marcha desenvolvida em direção a uma intensa restauração conservadora (APPLE, 2001, p.69) tem nos lançado em uma conjuntura de acirradas controvérsias e intrigantes contradições que alcançam várias esferas do campo educacional, como o currículo, as avaliações e a profissão docente.

Michael Apple denomina restauração conservadora a uma disputa sobre o controle da escola. Por um lado, atores e grupos sociais não somente alinhados com a ideologia da "economia de mercado" que reduz a ação do estado, recomenda a privatização, a livre escolha e defende o emprego da metodologia empresarial aos professores e alunos, exaltando a competição e produzindo rankings. Por outro lado, uma frente neoconservadora que requer um estado forte para agir sobre o controle dos sujeitos, defendendo a "liberdade", desde que sejam reforçados os valores da família e da religião, sob o argumento de recuperação moral da sociedade.

Nesse contexto maior de inquietações, refletir sobre a ações e os discursos que vêm impactando as políticas que balizam o Ensino de Ciências e Biologia no país é algo que nos move. De nossa ótica, é preciso indagar e compreender como os deslocamentos que serão operados nesse acirrado quadro de 
restauração conservadora (APPLE, 2001), isto é, nessa conjuntura em que neoliberais e neoconservadores, com apoio de líderes religiosos alinhados ao campo ideológico da direita e de uma classe média que defende regimes administrativos gerencialistas, vêm redefinindo políticas e práticas sociais, culturais e educativas de acordo com seus vieses ideológicos - que atacam o caráter progressista dos currículos escolares, aumentam a ingerência do âmbito privado sobre o público e alinham peremptoriamente a Educação aos seus interesses particulares (APPLE, 2001; 2017) ${ }^{1}$.

Especialmente nesse momento econômico, político e social do país, é preciso estarmos vigilantes à preservação dos princípios democráticos e atentos às narrativas que, produzidas por setores sociais que gostariam de resgatar um passado idealizado e pouco matizado, apontam o conservadorismo e a mercantilização como caminhos inevitáveis para as políticas curriculares brasileiras (APPLE, 2017). De acordo com Apple (2017) é preciso ainda, a partir de um reposicionamento dos nossos loci de enunciação, analisar as realidades sociais sob a perspectiva de quem sofre opressões por não integrar o bloco hegemônico que dita ideologicamente discursos, práticas e processos institucionais. Além disso, de acordo com o mesmo autor, é necessário localizar, interpretar e expor as relações e contradições de poder para então enxergarmos a Educação como ato político e ético que precisa criticamente apontar desigualdades, explorações e conflitos gerados por domínios e subordinações.

Neste texto, suscitamos uma reflexão sobre o avanço do conservadorismo e do reacionarismo, com protagonismo de setores religiosos, especialmente sobre os currículos das disciplinas escolares Ciências e Biologia, pensando seus ensinos no interior dessa conjuntura em que a dissolução das políticas públicas educacionais democráticas é uma tônica. A análise gira em torno de definições da Base Nacional Comum Curricular (BNCC) para essas disciplinas, no Ensino Fundamental II e no Ensino Médio. Argumentamos que para construir uma versão do ensino de Ciências e Biologia que estabeleça diálogos e aproximações significativas com as diferentes realidades que interpelam estudantes e escolas, contribuindo na resolução de problemas socioeducativos e ambientais, é preciso aprofundar a reflexão sobre as inúmeras consequências da impermanência da perspectiva laica nos sistemas educacionais.

Por isso, na primeira parte, trazemos à baila a histórica vulnerabilidade da laicidade na educação brasileira, apontando como essa já fora fragilizada pela BNCC e como a mesma compromete o ensino de Ciências e Biologia, principalmente no que tange à teoria da evolução. Na segunda, trazemos à tona uma reflexão sobre os impactos da perspectiva mecanicista e fragmentada de compreensão do corpo humano para a formação do alunado, mostrando como a mesma é aprodundada pela BNCC. Ainda nessa seção, abordamos o ataque conservador no que concerne às questões de gênero e sexualidade. Na terceira, focalizamos os debates sobre relações étnico-raciais que atravessam os cotidianos escolares, completando a análise de um quadro de dimensões das realidades educacionais que foram progressivamente apagadas tanto da BNCC em geral, quanto da sua parte especificamente destinada às Ciências da Natureza. 
Enfim, tecemos reflexões que visam contribuir para reafirmar uma educação pública, laica, plural e democrática. Também sinalizamos que algumas ameaças relacionadas à fragilidade da laicidade do Estado têm dificultado a concretização de práticas pedagógicas que possam enriquecer as experiências de docentes e discentes junto às demandas em prol de justiça social e igualdade para todos e todas.

\section{Evolução biológica: uma temática hipersensível ao conservadorismo}

O fenômeno religioso traz embates e dilemas para dentro das escolas ao penetrar os diferentes cotidianos escolares (ANDRADE e TEIXEIRA, 2014). Ao mesmo tempo, tem se reforçado discursos que argumentam em prol da presença da religião nos currículos escolares como um dispositivo para a remissão moral das juventudes ou um antídoto para a crise social, cada vez mais eloquente e atribuída por alguns setores conservadores como consequência da "falta de Deus" na sociedade (CUNHA, 2014).

Por mais que reconheçamos que o diálogo com as diversas crenças e religiões nos espaços escolares possa constituir oportunidades para a promoção e o estabelecimento de processos que culminem em uma desejável superação de preconceitos e discriminações (ANDRADE e TEIXEIRA, 2014), complexificar esse debate se faz necessário para não cairmos em algumas armadilhas discursivas que têm fortalecido a ingerência do âmbito privado sobre público. Nesse sentido, urge observar que, por exemplo, alianças entre grupos religiosos possibilitaram uma forte articulação em torno do Ensino Religioso nas escolas públicas do Rio de Janeiro, com implicações para o ensino de Ciências e Biologia, conforme indicam Selles, Dorvillé e Pontual (2016).

Tal mobilização acirrou a disputa pelo espaço público com defensores da laicidade e passou a trazer para dentro das abordagens de Ensino Religioso elementos de confronto entre as perspectivas criacionista e evolutiva, indo além das tradicionais discussões relacionadas à cidadania e à liberdade religiosa (SELLES, DORVILLÉ e PONTUAL, 2016). De todo modo, é interessante ressaltar que por mais que nossas discussões sejam inerentes à defesa da laicidade nas escolas públicas, Vieira e Falcão (2012) demonstram como a compreensão da teoria evolutiva pode ser fortemente obstruída e dificultada em escolas particulares que optam institucionalmente por ensinar e realçar o criacionismo. Os imbróglios analisados pelas autoras são devidos a questões ideológicas relacionadas à religiosidade e não a problemas ou obstáculos didático-pedagógicos. Assim, as autoras argumentam que o debate em torno da necessidade da laicidade deve ser ampliado tendo em vista o confronto proposital entre ciência e religião que é corriqueiramente construído nos espaços educacionais confessionais.

Feita essa observação, é importante salientar que o ensino de teoria evolutiva está sob constante risco: seja por conta de projetos de lei como o de número 8.099/2014 (BRASIL, 2014), de autoria de um deputado-pastor, que pretende obrigar o ensino do criacionismo em instituições educacionais públicas e 
privadas, inclusive com o mesmo status das teorias científicas; seja pelo constrangimento de organizações como o "Escola Sem Partido", que pressionam professores de Ciências e Biologia a não lecionarem ou a superficializarem o trabalho com conteúdos ligados à evolução biológica, alegando que estudantes seriam violados pela ação de docentes que se aproveitariam da liberdade de cátedra e da audiência cativa dos alunos para incutirem valores contrários àqueles recebidos no âmbito familiar. Tem-se configurado portanto, uma cultura de auditoria alavancada pelo crescente poder do senso comum direitista que aflige e tenta intimidar o trabalho docente comprometido com a consolidação de uma educação cada vez mais plural, inclusiva, socialmente situada e justa (APPLE, 2015; 2017).

Contudo, Teixeira (2016) pondera que durante sua pesquisa de doutoramento, relacionada à investigação de como se dá o ensino e a aprendizagem da teoria evolutiva em colégios estaduais do Rio de Janeiro, foram presenciados poucos conflitos explícitos entre docentes e discentes nas aulas sobre evolução biológica. No entanto, conflitos "velados" e "intensos", nas palavras do autor, puderam ser apreendidos, principalmente diante da significativa presença de estudantes evangélicos pentecostais e neopentecostais, que ofereceram maior resistência aos ensinamentos sobre evolução biológica.

Destacamos as considerações de Teixeira (2016) sobre o papel do professor que entram em sintonia com a defesa da escola laica. Para ele, o trabalho docente deve mirar a diferenciação entre conhecimentos religiosos e científicos para que os estudantes sejam estimulados a compreender as teorias científicas sem se sentirem impelidos à negação de suas crenças pessoais. Afinal, se uma escola laica não pode conviver com posturas dogmatizadas, nem nutrir a percepção de que existam verdades absolutas, todo o esforço (e desafio) é o de promover uma cultura docente que aceite a diferença, mas que também dela se fortaleça.

Estudos como os de Dorvillé e Selles (2016), também reforçam que práticas pedagógicas que melhorem a compreensão de como se constituem e se realizam as atividades científicas são importantes para que o ensino de evolução possa ser significativo e, além disso, consiga se contrapor às crescentes pressões das comunidades evangélicas e adventistas para que o criacionismo seja ensinado em todas as escolas do país. Tais atividades, também em sintonia com a laicidade, serviriam para a promoção do respeito pelas diferentes formas de compreender o mundo e a vida, ao mesmo tempo em que promoveriam estranhamentos e desabilitariam zonas de conforto a partir do diálogo com os conhecimentos científicos. Por isso, uma escola laica não desqualifica as ideias religiosas ou as crenças pessoais dos estudantes (TEIXEIRA e LEVINSON, 2018).

Contudo, é preciso mencionar que nenhum outro grupo organizado, exceto o formado pelas denominações evangélicas supracitadas, vivenciou em tão curto período de tempo tamanho sucesso na colonização e exploração de espaços e instâncias públicas e privadas de poder e decisão, obtendo popularização e destaque no cenário político e social por mais que um certo "mal estar" possa ter sido 
gerado (CAVALIERE, 2007). A crescente influência do protestantismo conservador na educação brasileira também desafia, impacta e interpela professores de Ciências e Biologia que enfrentam em suas salas de aula interpretações criacionistas - comumente doutrinárias e fundamentalistas - oriundas do literalismo bíblico protestante sobre a origem da vida e das espécies, divergentes das explicações evolutivas (DORVILLÉ e SELLES, 2016; SELLES, DORVILLÉ e PONTUAL, 2017).

De acordo com Teixeira e Andrade (2014), apesar de professores de Ciências e Biologia reconhecerem a importância da teoria evolutiva e de seu ensino, não há consenso quanto à anuência ou não em relação ao ensino do criacionismo. Ademais, Dorvillé e Selles (2016) apontam que alguns problemas na qualidade do ensino de evolução biológica também têm sido resultado do crescente número de docentes vinculados a denominações cristãs que acreditam literalmente no relato bíblico para a criação do universo e o surgimento da vida.

Nesses casos, evidentemente, não apenas os debates em torno da evolução biológica ficam comprometidos, mas também os demais assuntos controversos que às vezes são suscitados nas aulas de Ciências e Biologia, como questões ligadas a gênero e sexualidade, e acabam sendo constrangidos por visões religiosas fundamentalistas demonstradas por alguns docentes. Por isso, mais uma vez, a defesa da laicidade na educação se faz necessária. Afinal, cabe reconhecer que "há implicações educacionais na leitura literal da Bíblia que não se circunscrevem ao privado, mas que afetam peremptoriamente o direito de alunos de escolas públicas a uma formação que não censure ou limite a qualidade da abordagem dos conteúdos biológicos" (DORVILLÉ e SELLES, 2016, p. 445).

Assim, a escola pode e deve ser um espaço que possibilite o contato dos alunos com diversos modos de pensar, o que só é viável se não permitirmos que determinadas religiões sejam privilegiadas ou pautem a cultura escolar, com suas tradições e particularidades. Portanto, o ensino de Ciências e Biologia pode ser o espaço para que os estudantes, em sua variedade de trajetórias e identidades, complexifiquem seus saberes e conhecimentos, ampliando as lentes com as quais podem enxergar e decifrar o mundo que os rodeia e a sociedade que os condiciona.

A despeito de todas essas notáveis compreensões, a formulação das políticas públicas educacionais no presente parece caminhar justamente no sentido contrário, como ilustra a reforma curricular instituída pela BNCC. Antes de tratarmos especificamente do retrocesso que ela representa em termos de conquistas democráticas recentes no âmbito do currículo, é preciso destacar que essa reforma, embora tenha sido aprovada no governo de Michel Temer (MDB), foi proposta ainda no governo de Dilma Rousseff (PT).

Em setembro de 2015, veio a público a primeira versão do documento, contendo direitos de aprendizagem e objetos de conhecimentos para todas as etapas da Educação Básica, ano a ano, para cada componente curricular. Nessa versão, conforme destaca Cunha (2016), cometeu-se a aberração 
epistemológica de inserir o Ensino Religioso como componente curricular da área de conhecimento de Ciências Humanas - em total descaso, ainda, com dispositivos legais precedentes como as Diretrizes Curriculares Gerais da Educação Básica (BRASIL, 2013) que preveem uma área de conhecimento especificamente destinada ao Ensino Religioso. Na segunda versão do documento, divulgada em abril de 2016, esse "equívoco" foi revertido e uma área de conhecimento específica foi destinada ao Ensino Religioso.

Após a deposição da presidente petista, algumas mudanças aconteceram na reforma curricular em curso. Após a entrega do Ministério da Educação (MEC) à coalizão liberal-conservadora representada nas figuras de Mendonça Filho e Maria Helena Guimarães de Castro (que fora integrante da equipe de Paulo Renato Souza, ministro da Educação no governo de Fernando Henrique Cardoso), o Novo Ensino Médio (NEM) foi aprovado via Medida Provisória em setembro de 2016 (BRASIL, 2016).

A terceira versão da BNCC - a primeira no governo Temer - definiu competências e habilidades apenas para a Educação Infantil e para o Ensino Fundamental (BRASIL, 2017). Nessa, o Ensino Religioso foi retirado, sob a alegação de que, conforme define Lei de Diretrizes e Bases da Educação Nacional (BRASIL, 1996), o mesmo deveria ser oferecido "no Ensino Fundamental nas escolas públicas em caráter optativo, cabendo aos sistemas de ensino a sua regulamentação e definição de conteúdos" (Art. 33, § $1^{\text {o }}$ - grifo nosso), de modo que "não cabe à União estabelecer base comum para a área, sob pena de interferir indevidamente em assuntos da alçada de outras esferas de governo da Federação" (BRASIL, 2017a, p. 25).

Em que pese a decisão do Supremo Tribunal Federal (STF) de autorizar o ensino confessional religioso nas escolas públicas em setembro de $2017^{2}$, continua não cabendo à União definir diretrizes para área, o que evidencia quão contraditória e tensa é esta questão. Mesmo assim, o Ensino Religioso foi inserido como área de conhecimento na versão da BNCC homologada, com competências e habilidades específicas a serem desenvolvidas em cada ano do Ensino Fundamental em total descaso com os dispositivos legais precedentes (ANDRADE e MOTTA, 2018).

À área de conhecimento Ensino Religioso está relacionada apenas um componente curricular, qual seja, o Ensino Religioso:

A partir da década de 1980, as transformações socioculturais que provocaram mudanças paradigmáticas no campo educacional também impactaram no Ensino Religioso. Em função dos promulgados ideais de democracia, inclusão social e educação integral, vários setores da sociedade civil passaram a reivindicar a abordagem do conhecimento religioso e o reconhecimento da diversidade religiosa no âmbito dos currículos escolares. A Constituição Federal de 1988 (artigo 210) e a LDB nº 9.394/1996 (artigo 33, alterado pela Lei $n^{\circ} 9.475 / 1997$ ) estabeleceram os princípios e os fundamentos que devem alicerçar epistemologias e pedagogias do Ensino Religioso, cuja função educacional, enquanto parte integrante da formação básica do cidadão, é assegurar o respeito à diversidade cultural religiosa, sem proselitismos (BRASIL, 2017b, p. 433 - grifos nossos). 
Para esse componente curricular nos anos finais do Ensino Fundamental são estipulados determinados pressupostos, como "Contribuir para que os educandos construam seus sentidos pessoais de vida a partir de valores, princípios éticos e da cidadania” (BRASIL, 2017b, p. 435). Com base nesses, são estabelecidas Competências Específicas da área, como "Reconhecer e cuidar de si, do outro, da coletividade e da natureza, enquanto expressão de valor da vida" e "Analisar as relações entre as tradições religiosas e os campos da cultura, da política, da economia, da saúde, da ciência, da tecnologia e do meio ambiente" (BRASIL, 2017b, p. 435).

As Unidades Temáticas desse componente curricular são (i) Identidades e Alteridades, (ii) Manifestações Religiosas e Crenças Religiosas e (iii) Filosofias de Vida (BRASIL, 2017b, p. 437). A cada uma delas são relacionados alguns objetivos de aprendizagem como "Liderança e direitos humanos", "Doutrinas religiosas" e "Princípios éticos e valores religiosos" (BRASIL, 2017b, p. 452). Aos objetivos foram associadas determinadas habilidades a serem desenvolvidas pelo alunado, dentre as quais estão "Identificar princípios éticos em diferentes tradições religiosas e filosofias de vida, discutindo como podem influenciar condutas pessoais e práticas sociais", "Exemplificar líderes religiosos que se destacaram por suas contribuições à sociedade" (BRASIL, 2017b, p. 453) e, no último ano dessa etapa, “Construir projetos de vida assentados em princípios e valores éticos” (BRASIL, 2017b, p.457).

Partindo de uma análise do documento legal, podemos encontrar pistas das finalidades da inserção desse componente na BNCC que podem indicar prováveis colisões com os entendimentos vigentes no campo do Ensino de Ciências e Biologia em relação às contribuições que ambas disciplinas escolares podem oferecer:

No conjunto das crenças e doutrinas religiosas encontram-se ideias de imortalidade (ancestralidade, reencarnação, ressurreição, transmigração, entre outras), que são norteadoras do sentido da vida dos seus seguidores. Essas informações oferecem aos sujeitos referenciais tanto para a vida terrena quanto para o pós-morte, cuja finalidade é direcionar condutas individuais e sociais, por meio de códigos éticos e morais. Tais códigos, em geral, definem o que é certo ou errado, permitido ou proibido. Esses princípios éticos e morais atuam como balizadores de comportamento, tanto nos ritos como na vida social (BRASIL, 2017, p. 438 - grifos nossos).

Assim, seguindo a lógica interna do documento, vemos que o Ensino Religioso também pretende se consolidar como estratégico (DE CERTEAU, 1998) para a conformação de determinados tipos de pensamentos, bem como para a formatação de certos hábitos e posturas de vida. Por outro lado, como sinalizam Dorvillé e Selles (2016), ensinamos Ciências e Biologia também para que os alunos desenvolvam um pensamento crítico capaz de problematizar, partindo de suas lógicas e pressupostos próprios, até mesmo versões hegemônicas da própria atividade científica, que é situada historicamente. 
Tais disciplinas conseguiriam conversar produtivamente com outras que não partem dos mesmos pressupostos?

Ao findar as considerações relativas ao ensino da teoria evolutiva, cabe afirmar que essa não é a única temática tratadas nas disciplinas escolares Ciências e Biologia que tem sido alvejada pelo enrijecimento da articulação de setores políticos e sociais comprometidos com ideologias não laicas, como veremos adiante.

\section{O direito ao reconhecimento da pluralidade nos/dos corpos humanos: uma questão posta}

O fortalecimento do Ensino Religioso e a legitimação de sua confessionalidade na escola afeta a seleção de conteúdos e métodos do ensino de Ciências e Biologia mais do que podemos imaginar. Isso ocorre, segundo Selles, Dorvillé e Pontual (2016), porque os confrontos entre as ideias religiosas e científicas passam a ser institucionalizados, como se fossem sustentadas por bases teóricas e epistemológicas equivalentes, e extrapolam o domínio do debate individual, acarretando coerções sobre os processos decisórios de professores de Ciências e Biologia no tratamento dos conteúdos disciplinares e na produção cotidiana dos currículos escolares. Assim, o trato de assuntos que colidem com óticas religiosas conservadoras tende a tornar-se facultativo e negligenciado, enquanto explicações e discussões biológicas ou socioculturais tornam-se negadas.

Contrapondo-se a esse panorama, Apple (2017) defende que os currículos devem levar em consideração as demandas daqueles que não são privilegiados pelos padrões hegemônicos de classe social, de raça, de sexualidade e de gênero e se responsabilizar de modo ético e político para que haja uma verdadeira transformação social que permita a inclusão de sujeitos que passam por processos de desumanização dentro e fora da escola. Tal responsabilidade, a cargo de tantas disciplinas escolares, parece recair fortemente no trabalho efetuado por inúmeros professores de Ciências e Biologia quando abordam aspectos relativos às questões humanas.

Dentre as temáticas comumente debatidas quando ensinamos essas disciplinas e que acabam sendo enfraquecidas ou silenciadas se encontram aquelas tradicionalmente encarregadas de trabalhar aspectos do funcionamento do corpo humano e que tangenciam reflexões relacionadas a gênero, sexualidade, raça e etnia. A propósito, de acordo com Aquino et al (2014), as discussões contemporâneas sobre cultura e identidade acessam o ensino de Ciências e Biologia intermediadas pelo viés da saúde, fazendo com que múltiplas indagações atravessem o corpo material de "carne e osso". No entanto, o tema da sexualidade humana é um saber cada vez mais negociado no ambiente escolar (BASTOS e ANDRADE, 2016).

Nesse sentido, para Bastos (2015) é importante que tais disciplinas escolares agreguem aos conteúdos tradicionais uma discussão sobre a diversidade sexual que vá além dos padrões 
heteronormativos e traga uma perspectiva de cidadania científica, intercultural e plural para o ensino e a aprendizagem das Ciências da Natureza. O autor argumenta que uma educação que não estabeleça um profundo diálogo sobre a diversidade cultural, sobre a igualdade articulada com as diferenças relativas ao gênero, às formas do corpo ou à afetividade e sobre a constante capacidade de mudança das classificações sociais não pode ser considerada desejável. Para ele, as diferenças sexuais devem ser encaradas como integrantes do conhecimento escolar e, portanto, evoca uma pedagogia da sexualidade para trazer reflexões sobre a forma como as sexualidades são afirmadas ou silenciadas na escola, mesmo fazendo parte das experiências humanas e escolares.

Bastos (2015) problematiza ainda a "natureza polêmica" da pluralidade sexual e os tabus fortemente fomentados pelos vieses religiosos - do ambiente escolar ao reconhecer os conhecimentos como construções culturais, sociais e históricas, e estranhar naturalizações que materializam preconceitos e normatizam pressupostos sobre esses temas. Com base nesse entendimento, defendemos a necessidade de que o Ensino de Ciências e Biologia se comprometa com a discussão de dimensões sociais, políticas e econômicas sobre ciência, tecnologia, cultura e sociedade.

Todavia, é preciso refletir sobre como travaremos essas discussões e concretizaremos essa proposta frente ao cenário que se desenha, uma vez que a influência vigorosa de movimentos neoconservadores tem insistido que em nossas aulas só deve haver a disseminação de um determinado tipo de conhecimento, tido como "neutro", da anatomia e da fisiologia humana, gerando uma pressão que intensifica a exclusão de questões culturais que atravessam a constituição plural dos sujeitos, que são biológicos, mas também sociais.

No que tange a essas compreensões, a versão aprovada da BNCC também representa um grande retrocesso. Em 2015, à época da divulgação da primeira versão, Ricardo Fazetta, gerente de conteúdo do movimento Todos Pela Educação (TPE), aliado a interesses empresariais na educação, elogiou, em nome do TPE, o movimento do MEC de incluir na BNCC as discussões sobre gênero, afirmando que a inclusão representava um avanço em direção ao combate do preconceito, mas que também geraria polêmica: "a discussão vai ser boa e tem que acontecer. O que não pode é omitir de partida. Tem que retomar, discutir e defender, mostrando os argumentos" (O GLOBO, G1, 2015, s./p.). Evidenciando as tensões e os conflitos entre as duas frentes previamente mencionadas que disputam o controle sobre a escola, na primeira versão divulgada no governo Temer houve supressão das questões de gênero em meio a uma sequência de notícias que se sucederem na grande imprensa, tais como: "Bancada religiosa pediu a Temer retirada de questão de gênero da Base"; "Governo Temer esvazia gênero na base curricular e mistura tema com religião" (SALDAÑA, 2017); "Bancada evangélica celebra retirada de questão de gênero da base curricular" $" 3$ e outros. 
Apesar da manifestação da Organização das Nações Unidas (ONU) e de diversos atores da sociedade civil sobre a influência de ideias conservadoras na $\mathrm{BNCC}^{4}$, a versão aprovada não só manteve esses retrocessos como avançou ainda mais ao retirar também as questões de sexualidade. O tema "Saúde e Sexualidade", até então listado entre os "Temas Contemporâneos", foi retirado da versão final, aprovada em dezembro.

Outras mudanças também são relevantes, tais como a ocorrida em uma das habilidades previstas para o componente curricular Ciências da Natureza. Na versão divulgada em abril de 2017, estava previsto "Selecionar argumentos que evidenciem as múltiplas dimensões da sexualidade humana (biológica, sociocultural, afetiva e ética) e a necessidade de respeitar, valorizar e acolher a diversidade de indivíduos, sem preconceitos baseados nas diferenças de gênero" (BRASIL, 2017a, p.300). Na versão final, a habilidade prevista é apenas "Selecionar argumentos que evidenciem as múltiplas dimensões da sexualidade humana (biológica, sociocultural, afetiva e ética)” (BRASIL, 2017b, p. 347).

Em suma, apesar do bordão de que a "Base não é Currículo" ser incansavelmente repetida pelos atores do MEC (2018), as disputas mencionadas anteriormente mostram a limitação desse entendimento acerca do currículo, pois longe de ser uma listagem de conteúdos a serem seguidos na escola, significa uma construção social em meio a embates e inúmeros conflitos. Assim, não estipular na BNCC que as discussões sobre gênero e sexualidade sejam parte do conteúdo obrigatório da Educação Básica, além de materializar o conflito de grupos pelo controle do currículo, retira parte do respaldo legal de docentes e escolas que entendam a necessidade de abordar esse conteúdo, além de esvaziar as suas importância e legitimidade.

Por isso, um caminho pavimentado por desafios e dilemas deverá ser trilhado por professores de Ciências e Biologia comprometidos com a defesa da pluralidade de ideias, com a diversidade humana e com a inclusão dos marginalizados sociais. Inclusive para que seja superada a hegemonia da abordagem biomédica sobre corpo humano, que acompanha uma clássica visão de saúde higienista e de educação comportamentalista nos currículos escolares de Ciências e Biologia (VILELA e SELLES, 2015).

Porém, cabe ressaltar que os modos como os conhecimentos científicos sobre o corpo humano são trabalhados no contexto escolar, apesar de serem tidos como fragmentados, mecanicistas, reducionistas e produtores de um discurso idealizado que não corresponde aos corpos reais (MACEDO, 2005), sofrem transformações e configuram-se como conhecimentos escolares a partir de influências sociais diversas. A produção histórica das disciplinas escolares se dá em um espaço de negociação entre os conhecimentos e as tradições científicas, os saberes cotidianos, o modus operandi da escola e seus aspectos organizacionais e didáticos, como elementos da própria cultura escolar, evidenciando o dinamismo da construção do currículo. 
Por isso, o trabalho com abordagens sociais e culturais sobre o corpo e a saúde interpela, segundo Vilela e Selles (2015), os discursos hegemônicos sobre o "corpo humano escolar" e as concepções sobre o que é lícito e saudável. Assim, colocar certas tradições que têm habitado as salas de aulas em diálogo com fatores sociais e culturais nos quais os estudantes estão imersos faz-se cada vez mais necessário diante do reconhecimento de que o Ensino de Ciências e Biologia é atravessado por questões de ordens diversas que tendem a ser ignoradas por docentes ou "apagadas" das escolas com o recrudescimento da restauração conservadora (APPLE, 1994).

\section{Etnia e raça: deslizamentos para operar branqueamentos nos currículos escolares}

Assim como as investidas conservadoras contra o ensino da evolução biológica e o silenciamento das questões de gênero e sexualidade que interpelam os conteúdos sobre o corpo humano, outro ponto que precisa ser mencionado, mesmo que a limitação de nosso espaço nos prive de realizar uma discussão mais pormenorizada como seria desejável, está relacionado às questões étnico-raciais. Especialmente a partir dos anos 2000, tais questões vêm assumindo destaque para o Ensino de Ciências e Biologia. A intensidade dos debates sociais atinge os cotidianos escolares e vem provocando processos de ruptura epistemológica e curricular que trazem assuntos, sujeitos e práticas comumente marginalizadas e discriminadas para as disciplinas Ciências e Biologia.

Aliás, Gomes (2012) ressalta que movimentos de descolonização dos currículos da educação brasileira vêm exigindo mudanças nas representações e práticas sobre a África e os afro-brasileiros, além de questionar lugares de poder ao indagar as relações entre direitos e privilégios presentes na cultura política e educacional brasileira que alcança escolas e universidades. Assim, à educação para as relações étnico-raciais se soma o desafio posto à educação escolar já abordado antes neste texto: estabelecer um diálogo entre escola, currículo e realidade social para que reflitamos sobre culturas negadas e silenciadas nos espaços escolares e nas instituições educacionais.

Não se pode ignorar que a discriminação racial, o racismo ambíguo brasileiro e o mito da democracia racial são pontos que modulam a seletividade das instituições educacionais e propiciam rituais pedagógicos a favor da discriminação racial. Contudo, a Lei 10.639/2003 (BRASIL, 2003) trouxe uma oportunidade de diálogo intercultural para a construção de uma alternativa da história do mundo (GOMES, 2012). Assim, para Verrangia e Silva (2010), o Ensino de Ciências pode promover a educação das relações étnico-raciais quando a entende como direito humano fundamental e como pressuposto para a formação para a cidadania.

A BNCC também reforça esses problemas, que vêm sendo sinalizados e tensionados desde a primeira versão, de modo especial no componente curricular História. Sobre esse componente, à época da 
divulgação das duas primeiras versões, o então ministro da educação Aloizio Mercadante afirmou que houve melhoras entre a primeira e a segunda versão, pois refez-se a ordem cronológica dos conteúdos, evitou-se o "viés eurocêntrico e incorporou-se a valorização da África, o protagonismo das culturas indígenas e afro-brasileiras, mas sem abrir mão dos processos históricos do Ocidente e do Brasil" (RODRIGUES, 2016, s./p).

No entanto, sobre a mesma versão, a Associação Nacional de História (ANPUH) afirmou que, embora tivessem sido consideradas algumas críticas, outras "foram obliteradas, sobretudo, aquelas relacionadas a uma reflexão mais ampla acerca do conceito de eurocentrismo - notadamente presente nesta segunda versão - e sobre a importância da tematização do tempo como um conceito fundamental para o estudo e ensino da história" (ANPUH, 2016, s./p.), bem como que toda a Era Vargas havia sido suprimida e que as definições do documento preservavam estereótipos construídos na historiografia do século XIX.

Sobre as versões do governo Temer, Cruz (2017) salienta que embora o tema das relações étnicas e raciais tenha ascendido no debate educacional brasileiro, e tenha sido mantido no âmbito dos Temas Contemporâneos como "Educação das relações étnico-raciais e ensino de história e cultura afro-brasileira, africana e indígena" (BRASIL, 2017b, p. 19), esses temas aparecem de forma residual em comparação com outros temas especialmente na proposta dirigida ao ensino de história.

Tal debate não se circunscreve à disciplina escolar História, pois as temáticas raciais encontram-se presentes nas disciplinas Ciências e Biologia há mais de um século, tanto reiterando os movimentos eugênicos (SANTOS, 2013) quanto, mais recentemente, incorporando críticas ao racismo (LEVY, SELLES e FERREIRA, 2008). Essas disciplinas certamente poderiam também ser comprometidas com a reversão do viés eurocêntrico e dos preconceitos de raça, gênero e classe, pois há um rol de questões que podem ser abordadas em aulas de Ciências e Biologia quando assumimos o compromisso de reverter o paradigma cultural eurocentrado vigente. Nesse sentido, a promoção de debates sobre as relações étnicoraciais nessas disciplinas permite a identificação das contribuições trazidas pelos negros para a construção do Brasil e incentiva o reconhecimento da diversidade cultural afro-brasileira para que as atuais e futuras gerações de afrodescendentes possam criar um novo campo imagético de si (BENVENUTO e AYRES, 2014).

Como pautaremos nossas práticas pedagógicas, enquanto professores de Ciências e Biologia, para implementarmos essas contribuições para o fortalecimento da educação antirracista também é uma questão difícil e complexa de ser respondida no panorama atual. Com grupos cristãos fundamentalistas cada vez mais empoderados e articulados politicamente, tem sido cada vez recorrente encontrar relatos e denúncias de discriminação e perseguição religiosa aos praticantes de cultos e credos de matriz africana. 
Porém, a escola tem que ser um local seguro para aqueles que não professam a fé de matriz judaico-cristã ou não dissimulam suas experiências de cunho religioso divergentes da religiosidade tida por padrão. Por isso, a laicidade é indispensável para a garantia da liberdade religiosa de todos que circulam pelos espaços escolares e é condição para que Ciências e Biologia sejam disciplinas capazes de abordar os debates étnico-raciais sem privilegiar visões hegemônicas a respeito do tema.

\section{Considerações finais}

A construção de uma educação pública, laica e plural é um processo que, por mais que apresente contradições, é também requisito indubitável para que nossas escolas sejam espaços de inclusão democrática e de reflexão sobre conhecimentos, saberes e tecnologias. O Ensino de Ciências e Biologia tem muito a contribuir para a concretização desse projeto, mas tem sido cada vez mais desafiado por questões sociopolíticas que lesam a autonomia do campo educacional e afetam os currículos nos cotidianos escolares.

Neste texto, vislumbramos possibilidades de diálogos que enfatizam a perspectiva laica de educação e argumentamos que a mesma é essencial para o trabalho em sala de aula com temáticas contemporâneas para o ensino de Ciências e Biologia tidas como controversas. Nesse sentido, focalizamos a importância da laicidade como uma espécie de "pré-requisito" para o ensino mais produtivo da teoria evolutiva e como condição sine qua non para que a abordagem de discussões relacionadas à identidade de gênero, sexualidade, corpo humano e saúde e relações étnico-raciais não reproduzam e legitimem estereótipos e preconceitos.

Como demonstram Piccinini e Andrade (2018), a BNCC apresenta uma série de problemas no que concerne ao encadeamento dos conteúdos do componente curricular Ciências da Natureza, que estão relacionados à passagem da organização vertical dos conteúdos à organização horizontal ${ }^{6}$. $\mathrm{O}$ tema corpo humano, por exemplo, que até então era abordado no oitavo ano do ensino fundamental, ao longo de todo o ano, foi repartido ao longo de todos os anos do Ensino Fundamental II. Além disso, o trabalho com as ideias evolucionistas básicas está previsto para o último ano do Ensino Fundamental, conquanto o Ensino Religioso acompanha todos os anos dessa etapa. Já o entendimento do funcionamento do corpo humano como um todo integrado, em viva e ativa relação com o ambiente, fica extremamente debilitado, posto que o documento prevê tão somente a abordagem de dois dos vários e complexos sistemas que formam os organismos humanos (BRASIL, 2017b, p. 342-349).

Por fim, empreendemos um movimento que almejou indicar como a produção da BNCC especialmente os documentos dirigidos às disciplinas escolares Ciências e Biologia - está atrelada ao fortalecimento de discursos relacionados a grupos sociais conservadores e/ou ligados ao empresariado 
que têm disputado uma crescente ingerência do âmbito privado sobre o público. Tal influência, que pretende promover apagamentos e silenciamentos de certas reflexões e debates nos espaços escolares, tem provocado contradições e tensões político-sociais para a profissão docente, a formação de professores e os currículos. Devemos, então, permanecer atentos a tais incursões, uma vez que as tentativas de restauração conservadora (APPLE, 2001) nos sistemas educacionais brasileiros podem culminar em graves ameaças aos princípios que garantem a oferta de educação pública, laica, gratuita, plural, de qualidade, democrática e socialmente justa e referenciada.

\section{Referências}

ANDRADE, Marcelo; TEIXEIRA, Pedro. A escola num mundo secular e religioso: poderia ser a tolerância uma alternativa? Teias (Rio de Janeiro. Impresso), v. 14, p. 61-79, 2014.

ANDRADE, Maria Carolina; MOTTA, Vânia. Base Nacional Comum Curricular e a Crise Orgânica do Capital: elementos para pensar o Ensino Religioso. Anais IX Colóquio Internacional Marx e Engels. Universidade Estadual de Campinas, 17 a 20 julho 2018.

APPLE, Michael. A luta pela democracia na educação crítica. Revista e-curriculum. São Paulo, v. 15, n. 4, 2017. pp. $894-926$.

APPLE, Michael. Reestruturação educativa e curricular e as agendas neoliberal e neoconservadora: entrevista com Michael W. Apple. Currículo sem Fronteiras. v.1, n. 1, 2001, pp. 5-33.

APPLE, Michael. Produzindo diferença: neoliberalismo, neoconservadorismo e a política de reforma educacional. Linhas Críticas. Brasília, n. 45. 2015. pp. 606-544.

AQUINO, Fernanda Etter Motta; ALVES, Luisa Lemos; FERREIRA, Marcia Serra; GOMES, Maria Margarida. Sentidos de sexualidade em produções acadêmicas: investigando os anais dos Encontros Nacionais de Ensino de Biologia (2005-2012). Revista de Ensino de Biologia da Associação Brasileira de Ensino de Biologia (SBEnBio), v. 7, p. 2085-2096, 2014.

ASSOCIAÇÃO NACIONAL DE HISTÓRIA (Anpuh). Manifestação Pública da Anpuh sobre a Base Nacional Comum Curricular. 2016. Disponível em: < https://www.anpuh.org.br/index.php/2015-01-2000-01-55/noticias2/noticias-destaque/item/3352-manifestacao-publica-da-anpuh-sobre-a-base-nacionalcomum-curricular>, acesso em 04 jan 2019.

BASTOS, Felipe. Diversidade sexual na prática de professores/as de Ciências: da polêmica ao (re)conhecimento escolar. In: Anais do 37ª Reunião Nacional da ANPEd, Florianópolis. 2015.

BASTOS, Felipe; ANDRADE, Marcelo. Cabe discutir gênero e diversidade sexual no ensino de Biologia? In: LIMA-TAVARES, Daniele; VILELA, Mariana Lima; AYRES, Ana Cléa Moreira; 
MATOS, Maria (Org.). Tecendo laços docentes entre ciência e culturas. 1ed.Curitiba: Prismas, 2016, v. , p. $159-183$.

BENVENUTO, Fabiana; AYRES, Ana Cléa Moreira. Currículo de Ciências e Relações Étnico-Raciais: uma relação em construção. Revista de Ensino de Biologia da Associação Brasileira de Ensino de Biologia (SBEnBio), v. 7, p. 1899-1910, 2014.

BOURDIEU, Pierre. O poder simbólico. Tradução de Fernando Tomaz. Rio de Janeiro: Bertrand Brasil, Rio de Janeiro, 1989.

BRASIL. Lei n. 9.394, 20 de dezembro de 1996. Estabelece as Diretrizes e bases da Educação Nacional. Brasília, DF: 1996.

BRASIL. Lei $\mathrm{n}^{\circ}$. 10.639, de 09 de janeiro de 2003. Altera a Lei no 9.394, de 20 de dezembro de 1996, que estabelece as diretrizes e bases da educação nacional, para incluir no currículo oficial da Rede de Ensino a obrigatoriedade da temática "História e Cultura Afro-Brasileira", e dá outras providências. 2003.

BRASIL. Ministério da Educação. Diretrizes Curriculares Nacionais Gerais da Educação Básica. Secretaria de Educação Básica. Diretoria de Currículos e Educação Integral. Brasília: MEC, SEB, DICEI, 2013. 542p.

BRASIL. Projeto lei n ${ }^{\circ}$ 8.099, de 13 de novembro de 2014. Ficam inseridos na grade curricular das Redes Pública e Privada de Ensino conteúdos sobre Criacionismo. 2014.

BRASIL. Ministério da Educação. Base Nacional Comum Curricular (3 $3^{a}$ versão -abril de 2017). Brasília, DF, 2017a. 396p.

BRASIL. Medida provisória $n^{\circ}$ 746, de 2016 (Reformulação do Ensino Médio). Institui a Política de Fomento à Implementação de Escolas de Ensino Médio em Tempo Integral, altera a Lei nº 9.394, de 20 de dezembro de 1996, que estabelece as diretrizes e bases da educação nacional, e a Lei no 11.494 de 20 de junho 2007, que regulamenta o Fundo de Manutenção e Desenvolvimento da Educação Básica e de Valorização dos Profissionais da Educação, e dá outras providências. 2016.

BRASIL. Ministério da Educação. Base Nacional Comum Curricular ( $3^{\text {a }}$ versão revista -dezembro de 2017). Brasília, DF, 2017b. 472p.

CAVALIERE, Ana Maria. O mal-estar do ensino religioso nas escolas públicas. Cadernos de Pesquisa (Fundação Carlos Chagas. Impresso), v. 37, p. 303-332, 2007.

CRUZ, Ana Cristina. O lugar da história e cultura africana e afro-brasileira nos debates contemporâneos do currículo brasileiro. Ensino Interdisciplinar, v. 3, nº. 08, Maio/2017.

CUNHA, Luiz Antonio. A laicidade em disputa: religião, moral e civismo na educação brasileira. Teias (Rio de Janeiro. Impresso), v. 14, p. 5, 2014.

A Entronização do Ensino Religioso na Base Nacional Curricular Comum. IN: Educação e Sociedade, Campinas, v. 37, nº. 134, p.266-284, jan.-mar., 2016. 
DE CERTEAU, Michel (1998). A invenção do cotidiano: artes de fazer. 3. ed. Petrópolis: Vozes.

DORVILLÉ, Luis Fernando; SELLES, Sandra Escovedo. Criacionismo bíblico, principais transformações ao longo do tempo e implicações para o ensino de Ciências e Biologia. Cadernos de Pesquisa, v. 46, p. 442-465, 2016.

FERREIRA, Marcia Serra. Currículo e cultura: diálogos com as disciplinas escolares Ciências e Biologia. In: MOREIRA, Antonio Flavio; CANDAU, Vera Maria (Org.). Currículos, disciplinas escolares $e$ culturas. 1ed.Petrópolis: Vozes, p. 185-213, 2014.

GOMES, Nilma Lino. Relações Étnico-Raciais, Educação e Descolonização dos Currículos. Currículo sem Fronteiras, v. 12, p. 98-109, 2012.

GOODSON, Ivor Frederick. Currículo: Teoria e História. Petrópolis: Vozes, 1995

GOODSON, Ivor Frederick. A Construção Social do Currículo. Lisboa: Educa, 1997

G1 EDUCAÇÃO. MEC lança documento preliminar da base nacional comum curricular. 2015. Disponível

em:

<http://g1.globo.com/educacao/noticia/2015/09/mec-lanca-documento-preliminar-da-base-nacionalcomum-curricular.html>, acesso em 02 jan 2019.

LEVY, Rachel Santos; SELLES, Sandra Escovedo; FERREIRA, Márcia Serra. Examining the ambiguities of the human race concept in biology textbooks: tensions between knowledge and values expressed in school knowledge. In: HAMMA, Marcus; REISS, Michael; BOULTER, Carolyn; TUNNICLIFFE, Sue Dale (Org.). Biology in Context: Learning and teaching for the twenty-first century. 1ed.Londres: Institute of Education University of London, 2008, v. 1, p. 338-346.

LOUREIRO, Carlos Frederico Bernardo; LIMA, Jacqueline Girão Soares de. Educação ambiental e educação científica na perspectiva Ciência, Tecnologia e Sociedade (CTS): pilares para uma educação crítica. Acta Scientiae (ULBRA), v. 11, p. 88-100, 2009.

MACEDO, Elizabeth. Esse corpo das Ciências é o meu? In: MARANDINO, Martha Marandino; SELLES, Sandra Escovedo; FERREIRA, Marcia Serra; AMORIM, Antonio Carlos Rodrigues (Org.). Ensino de Biologia: conhecimentos e valores em disputa. 1ed.Niterói: EdUFF, 2005, v. 1, p. 131-140.

MARANDINO, Martha; SELLES, Sandra Escovedo; FERREIRA, Marcia Serra. Ensino de Biologia: histórias e práticas em diferentes espaços educativos. 1. ed. São Paulo: Cortez, 2009. v. 1. 215p.

MIRANDA, Edgar. Educação científica e Cultura Política democrática: Um estudo sobre o processo de recontextualização de elementos de formação política na prática do ensino de ciências nas séries iniciais. Rio de Janeiro, 2018. Tese (Doutorado em Educação em Ciências e Saúde) Núcleo de Tecnologia Educacional para a Saúde - NUTES, Universidade Federal do Rio de Janeiro UFRJ, 2018. 
PICCININI, Cláudia; ANDRADE, Maria Carolina. O ensino de Ciências da Natureza nas versões da Base Nacional Comum Curricular, mudanças, disputas e ofensiva liberal- conservadora. REnBio - Revista de Ensino de Biologia da SBEnBio, vol. 11, n. 2, p. 34-50, 2018.

RODRIGUES, M. MEC apresenta segunda versão da base nacional comum curricular. 2016. Disponível:

<https://g1.globo.com/educacao/noticia/mec-apresenta-segunda-versao-da-base-nacional-comumcurricular.ghtml>, acesso em 04 jan 2019.

SANTOS, Maria Cristina Ferreira dos. A Biologia de Candido de Mello Leitão e a História Natural de Waldemiro Alves Potsch: Professores autores e livros didáticos - conhecimento e poder em disputa na constituição da Biologia escolar (1931 - 1951). (Tese de Doutorado). Universidade Federal Fluminense, 2013.

SELLES, Sandra Escovedo; FERREIRA, Marcia Serra. Disciplina escolar Biologia: entre a retórica unificadora e as questões sociais. In: MARANDINO Martha; SELLES, Sandra Escovedo; FERREIRA, Marcia Serra; AMORIM, Antonio Carlos Rodrigues. (Org.). Ensino de Biologia: conhecimentos e valores em disputa. Niterói: EDUFF, p. 50-62, 2005.

SELLES, Sandra Escovedo; DORVILLÉ, Luis Fernando; PONTUAL, Leandro Vahia. Ensino religioso nas escolas estaduais do Rio de Janeiro: novas implicações para o ensino de Ciências/Biologia. Ciência e Educação (UNESP. Impresso), v. 22, p. 875-894, 2016.

SEPULVEDA, Denize; SEPULVEDA, José Antonio. A disciplina Ensino Religioso: história, legislação e práticas. Educação (Santa Maria. Online), v. 42, p. 177-190, 2017

TEIXEIRA, Pedro. Aulas de evolução e religiosidade: conflitos velados e intensos. Revista de Ensino de Biologia da Associação Brasileira de Ensino de Biologia (SBENBio), v. 9, p. 2470-2482, 2016.

TEIXEIRA, Pedro; LEVINSON, Ralph. Crenças religiosas e evolução: um modelo para o diálogo em aula. Alexandria (UFSC), v. 11, p. 195-216, 2018.

VERRANGIA, Douglas; SILVA, Petronilha Beatriz Gonçalves. Cidadania, relações étnico-raciais e educação: desafios e potencialidades do ensino de Ciências. Educação e Pesquisa (USP. Impresso), v. 36, p. 705-718, 2010.

VIEIRA, Viviane; FALCAO, Eliane Brígida Morais. Laicidade e Ensino de Ciências: a necessária reflexão na escola privada. Alexandria (UFSC), v. 5, p. 83-100, 2012.

VILELA, Mariana Lima; SELLES, Sandra Escovedo. Corpo humano e saúde nos currículos escolares: quando as abordagens socioculturais interpelam a hegemonia biomédica e higienista. Bio-grafía: escritos sobre la biología y su enseñanza, v. 8, p. 113-121, 2015. 


\section{Notas:}

' Doutorando em Educação na Universidade Federal Fluminense (UFF). Mestre em Educação, licenciado e bacharel em Ciências Biológicas pela Universidade Federal do Rio de Janeiro (UFRJ).

ii Mestranda em Educação na Universidade Federal da Rio de Janeiro (UFRJ). Licenciada em Ciências Biológicas pela UFRJ.

iii Professora Titular do Programa de Pós-Graduação em Educação e da Faculdade de Educação da Universidade Federal Fluminense (UFF). Doutora pelo Center For Science Education da University of East Anglia (UEA). Bolsista de Produtividade (nível 1C) no CNPq e Cientista do Nosso Estado pela FAPERJ.

${ }^{1}$ Embora a ideia de "aliança" seja formulada por Apple, cabe dizer que no Brasil, as agendas desses grupos nem sempre são partilhadas integralmente. Entretanto, suas ações voltadas à educação se desenvolvem em uma rede convergente, conforme documenta Edgar Miranda (2018), ainda que divirjam sobre alguns temas, como por exemplo, a inclusão do criacionismo em aulas de Biologia e das temáticas de gênero na escola, essas evidenciadas pelo elogio de integrantes do movimento Todos pela Educação (O GLOBO, G1, 2015, s./p.).

${ }^{2}$ Mais informações podem ser encontradas na reportagem "STF decide que escolas públicas podem ter ensino confessional". Disponível em: <https://oglobo.globo.com/sociedade/educacao/stf-decide-que-escolas-publicas-podem-ter-ensinoconfessional-21878145>, acesso em 03 jan 2019.

${ }^{3}$ Disponível em: <http://www1.folha.uol.com.br/educacao/2017/04/1873511-bancada-evangelica-celebra-retirada-de-questaode-genero-de-base-curricular.shtml $>$.

${ }^{4}$ Disponível em: <http://agenciabrasil.ebc.com.br/educacao/noticia/2017-04/onu-alerta-para-impactos-do-projeto-escola-sempartido-na-educacao>. Acesso em 10 jun 2018.

5 Os temas contemporâneos definidos na BNCC devem ser incorporados aos currículos "preferencialmente de forma transversal e integradora. (...). Na BNCC, essas temáticas são contempladas em habilidades dos componentes curriculares, cabendo aos sistemas de ensino e escolas, de acordo com suas especificidades, tratá-las de forma contextualizada" (BRASIL, 2017 b, p. 20). O tema "gênero e sexualidade" integrou as três versões anteriores.

${ }^{6}$ Tradicionalmente, conteúdos da disciplina escolar Ciências intimamente afins são reunidos e trabalhados de modo integrado e contínuo dentro de cada ano do Ensino Fundamental II. Assim, convencionou-se que, por exemplo, os conteúdos relacionados ao funcionamento do corpo humano deveriam ser ensinados no $8^{\circ}$ ano, enquanto o $7^{\circ}$ ano se concentraria em trabalhar a biodiversidade. No entanto, a BNCC pulverizou tais conteúdos, desarticulando-os e disseminando-os por diferentes anos e descaracterizando os eixos temáticos de cada série. 